\title{
Protein Aggregation
}

\section{STUDIES OF LARGER AGGREGATES OF C-PHYCOCYANIN}

\author{
BY J. J. LEE AND D. S. BERNS \\ Division of Laboratories and Research, New York State Department of Health, \\ and the Department of Biochemistry, Albany Medical College of Union University, \\ Albany, N.Y. 12201, U.S.A.
}

(Received 27 May 1968)

\begin{abstract}
Aggregates of phycocyanin sedimenting at $17 \mathrm{~s}, 22 \mathrm{~s}$ and $27 \mathrm{~s}$ are demonstrated to constitute more than $40 \%$ of crude blue-green-algal extracts, $\mathrm{pH} 6.0$ and $I 0 \cdot 1$, and are retained in highly purified preparations. Sedimentation-velocity studies of the large aggregates as a function of pH are reported. Sucrose-density-gradient experiments performed as a function of time of sedimentation indicate that: (1) with increasing time of sedimentation, the largest aggregates are dissipated at the leading protein boundary and the several phycocyanin species present are not completely resolved; (2) phycocyanin fractions with the largest aggregates exhibit the highest $E_{620} / E_{280}$ ratio and the largest relative fluorescence efficiency. Gel-filtration experiments with Sephadex G-200 do not resolve the species completely, and reapplication of phycocyanin gel-filtration fractions to the column results in an elution pattern similar to the original, except that there is an enhancement of the allophycocyanin fraction and the amount of denatured protein. Increasing the sedimentation times in a sucrose density gradient also enhances the allophycocyanin fraction. Fluorescence results demonstrate that there are possibly three excitation maxima, one corresponding to the monomer (approx. 600 $\mathrm{m} \mu$ ), one for higher aggregates $(625-630 \mathrm{~m} \mu$ ) and one for the allophycocyanin fraction (approx. $650 \mathrm{~m} \mu$ ). Only a single fluorescence-emission band is detected, which is fairly symmetrical and which has a red shift with higher aggregation and with the appearance of allophycocyanin. The appearance of allophycocyanin may be correlated with the irreversible disaggregation of the largest phycocyanin species. It is suggested that the largest protein aggregates are in the size range of the biliprotein aggregates reported in electron microscopy of algal cells.
\end{abstract}

Evidence has been presented that aggregates of phycocyanin with sedimentation coefficients greater than $11 \mathrm{~s}$ are present in vitro (Berns \& Morgenstern, 1966; Berns \& Scott, 1966). [The use of the designations $6 \mathrm{~s}, 11 \mathrm{~s}$ etc. for the species present is nomenclature of convenience. Extrapolations to infinite dilutions were made in this work and previous studies (Scott \& Berns, 1965). Often sedimentation coefficients at a specific protein concentration differ very significantly from the extrapolated values. This behaviour is particularly true for the species that sediments more rapidly. The same species may be $6 \mathrm{~s}$ at one protein concentration and $\mathrm{pH}$, but $7 \mathrm{~s}$ at another. The reproducibility of extrapolations, the presence of the same species in dilute solution centrifugation work (Berns \& Morgenstern, 1966) and the use of the immunodiffusion technique to demonstrate the uniformity of species from different organisms
(Berns \& Scott, 1966; Berns, 1967) all support the assumption that $6 \mathrm{~s}$ or $7 \mathrm{~s}$ material is one species and $10 \mathrm{~s}$ or $11 \mathrm{~s}$ material etc. is another species or state of aggregation.] Substantial amounts of $19 \mathrm{~s}$ and $24 \mathrm{~s}$ material were found in phycocyanin preparations purified at $\mathrm{pH} 6 \cdot 0$ (Berns \& Morgenstern, 1966). The probable existence and importance of biliprotein aggregates larger than $11 \mathrm{~s}$ in vivo have been corroborated by electronmicroscopic studies by Gantt \& Conti (1967) and Luftig \& Haselkorn (1967).

We now report that most of the protein in crude extracts prepared in phosphate buffer, $\mathrm{pH} 6 \cdot 0$, has sedimentation coefficients of $11 \mathrm{~s}$ and above, and purification of the extracts by extended fractionation with ammonium sulphate gives phycocyanin preparations in which most of the material sediments above $11 \mathrm{~s}$. In earlier work with phycocyanin and other biliproteins the largest species reported was 
11s (Eriksson-Quensel, 1938; Hattori \& Fujita, 1959). [The origin and meaning of the nomenclature of the algal biliproteins, such as C-phycocyanin and allophycocyanin, are described in the reviews by Ó hEocha $(1962,1965)$. The interrelationship of the biliproteins from vastly different algal sources has been clarified by immunochemical techniques (Berns, 1967).]

\section{EXPERIMENTAL}

Phycocyanin was isolated and purified from cultures of Phormidium luridum with sodium phosphate buffer, $\mathrm{pH} \mathrm{6.0}$ and $I$ 0.1. Cell lysis, accomplished with lysozyme (Scott \& Berns, 1965), was allowed to proceed for about $5 \mathrm{hr}$. at room temperature in the presence of small amounts of buffer. The lysed cells and extract were stirred in additional buffer. The separation and precipitation of the major C-phycocyanin fraction were carried out as described by Berns \& Morgenstern (1966). Particular care was taken with extracts to centrifuge at approx. $2^{\circ}$ and $19000 \mathrm{~g}$ for approx. $30 \mathrm{~min}$. The purification of the phycocyanin after initial treatment with $50 \%$-saturated $\left(\mathrm{NH}_{4}\right)_{2} \mathrm{SO}_{4}$ included dialysis of concentrated solutions of phycocyanin in sodium phosphate buffer into $35 \%$-saturated $\left(\mathrm{NH}_{4}\right)_{2} \mathrm{SO}_{4}$ overnight at approx. $4^{\circ}$. The precipitate was separated from the supernatant by centrifugation at $19000 \mathrm{~g}$ for approx. $10 \mathrm{~min}$. and redissolved in buffer, and the resulting solution was centrifuged at $19000 \mathrm{~g}$ for $10 \mathrm{~min}$. The supernatant solution was recycled through this procedure at least five times. The $E_{620} / E_{280}$ ratio was $4 \cdot 1-4 \cdot 5$ for all purified preparations. (The extinction ratio is always reported at the visible-absorption maximum, which is approx. $620 \mathrm{~m} \mu$. It should be borne in mind that when shifts in the visible absorption band take place, although this ratio is indieated as $E_{620} / E_{280}$, the extinction at the wavelength of the measured absorption maximum is shown.) The absorption spectra of preparations were regularly examined with a Beckman DB spectrophotometer and a Cary model 14 spectrophotometer. Conventional analytical sedimentationvelocity experiments were performed and analysed as in previous work (Scott \& Berns, 1965). Sucrose-densitygradient experiments were performed with a Spinco model I-2 preparative ultracentrifuge according to the method of Martin \& Ames (1961). The sucrose-gradient $(5-20 \%$, w/v) sedimentation was allowed to proceed for $4,6 \cdot 5,10$ and $18 \mathrm{hr}$. at $39000 \mathrm{rev} . / \mathrm{min}$. in the SW 39 rotor. The absorption spectrum of each fraction from the sucrose-density-gradient sedimentation was monitored with a Cary model 14 spectrophotometer. Sedimentation-velocity experiments and sucrose-density-gradient experiments were also performed with pig thyroglobulin from the Worthington Biochemical Corp. (Freehold, N.J., U.S.A.) as well as with phycoerythrin purified from Porphyridium cruentum and Phormidium persicinum. These were control experiments to demonstrate the reproducibility of sedimentation coefficients for other biliproteins and proteins by both techniques. There was good agreement between the results of the two methods and literature values. The resolution of peaks in the sucrosedensity-gradient experiments was aided by plotting the derivative of the extinction of successive fractions and also the extinction at both ultraviolet- and visible-absorption maxima.
Gel-filtration experiments were performed at $4^{\circ}$ in a cold-room with Sephadex G-200 columns $(2.5 \mathrm{~cm} . \times 30 \mathrm{~cm}$.). The flow rates were usually $16-20 \mathrm{ml} . / \mathrm{hr}$. in sodium phosphate buffer, $\mathrm{pH} 6 \cdot 0$ and $I 0 \cdot 1$. The effluent was automatically monitored with an ultraviolet-absorption meter (GME model UV-2801F; Gilson Medical Electronics, Middleton, Wis., U.S.A.). Fractions collected from gelfiltration experiments were examined spectrophotometrically. The position of the visible-absorption maximum and the $E_{620} / E_{280}$ ratio were tabulated for each fraction. These fractions were also often examined in the ultracentrifuge. The Sephadex G-200 columns were calibrated with blue dextran, catalase, haemoglobin and myoglobin as markers of known molecular weight. These calibrations agreed well with the elution volume/void volume ratios reported by Andrews (1964).

The $\mathrm{pH}$ of all protein samples and buffers was measured with a Radiometer TTTIC $\mathrm{pH}$-meter.

Fluorescence measurements were performed with a Baird Atomic SF-1 spectrofluorimeter equipped with an R 136 photomultiplier from the Hamamatsu TV Co. (New York, N.Y., U.S.A.) and an X-Y recorder. All measurements were made in small quartz cells (approx. $0.5 \mathrm{ml}$. volume) on the original fractions from sucrose-densitygradient sedimentation without dilution whenever possible. Constant sensitivity settings were used for the entire series of measurements. The exciting wavelength for each fluorescence-emission-spectrum measurement was the one at which the visible-absorption maximum occurred. The excitation spectrum was measured by monitoring the fluorescence emission at $650 \mathrm{~m} \mu$ and by scanning the exciting wavelength from 250 to $650 \mathrm{~m} \mu$. A semiquantitative assessment of the quantum yield of the several fractions from the sucrose-density-gradient experiments was attempted by taking the ratio of the meter reading of emission intensity at the fluorescence-emission maximum to the extinction of the sample at the visible-absorption maximum. The extinction was measured in a $1 \mathrm{~cm}$. cell at the wavelength of this absorption maximum, the wavelength at which fluorescence was excited. During work on the sub-unit structure of phycocyanin in this Laboratory, $\mathrm{Dr}$ O. Kao performed fluorescence experiments with protein samples exhibiting typical phycocyanin absorption spectra and allophycocyanin absorption.

\section{RESULTS}

Purification. More than $40 \%$ of the material in all crude extracts of phycocyanin had sedimentation coefficients higher than $11 \mathrm{~s}$ (Table 1). Treatment with $50 \%$ - and $35 \%$-saturated ammonium sulphate eliminated the $3 \mathrm{~s}$ material and some of the $6 \mathrm{~s}$ material. The $E_{620} / E_{280}$ ratio increased as the relative amounts of the species sedimenting more rapidly increased. A narrower visible-absorption band width was evident as the percentage of higher aggregates increased. Repeated dialysis into 35\%-saturated ammonium sulphate was successful in preserving the large aggregates during prolonged purifications.

Gel filtration. In gel-filtration experiments the position of the absorption maxima in the region of 


\section{Table 1. Sedimentation-velocity studies of purification of phycocyanin}

All samples were in sodium phosphate buffer, $\mathrm{pH} 6.0$ and I 0.1. Results are for typical experiments at a single protein concentration of approx. $15 \mathrm{mg} . / \mathrm{ml}$. Previously reported sedimentation coefficients were $S_{25, \mathrm{w}}$ or $S_{25, \mathrm{w}}^{0}$ (Scott \& Berns, 1965, 1967; Berns \& Morgenstern, 1966). The present sedimentation coefficients are consistent with the earlier ones and the $S_{25, w}$ values may be converted into $S_{20, w}$ values by dividing by $1 \cdot 13$.

$\begin{array}{ccc}\text { Sample } & \boldsymbol{S}_{20, \mathrm{w}}(\mathrm{s}) & \begin{array}{c}\text { Relative \% of } \\ \text { total area }\end{array} \\ \text { Crude extract } & 3 \cdot 21 & 22 \\ & 5 \cdot 42 & 27 \\ & 10 \cdot 3 & 7 \\ & 15 \cdot 5 & 7 \\ & 19 \cdot 1 & 19 \\ \text { Purified phycocyanin } & 22 \cdot 6 & 18 \\ & 5 \cdot 28 & 27 \\ & 10 \cdot 2 & 12 \\ & 16 \cdot 0 & 13 \\ & 18 \cdot 9 & 24 \\ & 22 \cdot 2 & 24\end{array}$

$620 \mathrm{~m} \mu$ shifted to longer wavelengths in protein fractions having the smallest elution volumes. A small amount of opalescent material $(2-3 \%$ of the sample) always appeared at the void volume. This fraction contained some material that quickly sedimented and some that was very slow in sedimenting. Both types were obviously denatured. Reapplication of a fraction from one gel-filtration experiment to a column produced a larger amount of opalescent or denatured material (Figs. $1 b$ and $1 c$ ). Protein fractions that were eluted later (fraction 4, Table 2) gave at least some indication of an allophycocyanin spectrum. A typical gel-filtration elution pattern with a flow rate of approx. $20 \mathrm{ml} . / \mathrm{hr}$. is shown in Fig. 1. When the rate was slowed down to approx. $4 \mathrm{ml}$./hr. (Fig. la) slightly better resolution of peak areas was achieved. Repeated gel filtration of phycocyanin resulted in very little change in elution patterns, but appeared to enhance the amount of allophycocyanin (Fig. 1d). Sedimentation-velocity patterns demonstrated that $6 \mathrm{~s}, 11 \mathrm{~s}$ and $17 \mathrm{~s}$ species are present in fractions 2,3 and 4. It is significant that most of the $17 \mathrm{~s}$ material is found, not in fraction 2 , but instead in fraction 3 (Table 2 ). The $E_{620} / E_{280}$ ratio is usually a maximum where the $17 \mathrm{~s}$ material is present in the largest amount. Although samples applied to the Sephadex G-200 columns had large amounts of $24 \mathrm{~s}$ and $20 \mathrm{~s}$ material, none was detected in even the earliest eluted fractions (Table 2).

Sedimentation-velocity studies (schlieren optics). The results of sedimentation experiments carried

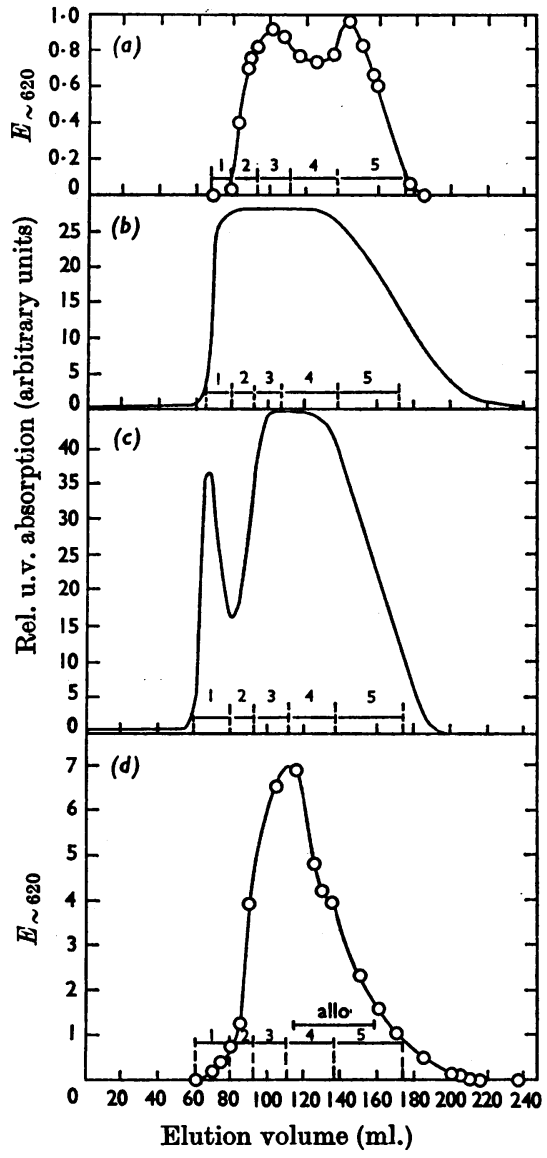

Fig. 1. Typical gel-filtration experiments with phycocyanin on Sephadex G-200, with sodium phosphate buffer, pH6.0 and $I 0 \cdot 1$, at approx. $4^{\circ}$. Sample concentrations are approx. $15 \mathrm{mg} . / \mathrm{ml}$. Flow rates are: in (a) approx. $4 \mathrm{ml} . / \mathrm{hr}$.; in (b), $(c)$ and $(d)$, approx. $20 \mathrm{ml} . / \mathrm{hr}$. In $(a)$ and $(d)$ extinction at the visible-absorption maximum (approx. $620 \mathrm{~m} \mu$ ) is plotted as a function of elution volume (in $\mathrm{ml}$.). The ordinate in (b) and (c) is the recorder tracing of the output of the $280 \mathrm{~m} \mu$ scanner used (GME model UV-2801F), which is relative ultraviolet absorption. (c) and (d) represent the same experiment analysed by the two different methods. The sample used in $(c)$ and $(d)$ consisted of the elution volume between 85 and $160 \mathrm{ml}$. in $(b)$, concentrated and reapplied to the same column. Sample fractions analysed by ultracentrifugation and spectrophotometry are indicated by the numbers 1, 2, 3, 4 and 5 above the horizontal lines. These fractions correspond to those listed in Table 2. Fraction 4 usually contains the major amount of allophycocyanin. However, reapplication of the sample to the column results in the spreading to fractions 4 and 5 noted in $(d)$.

out over a range of $\mathrm{pH}$ at constant ionic strength are presented in Table 3.

It was observed at all $\mathrm{pH}$ values that the relative 
Table 2. Typical Sephadex G-200 gel-filtration experiment with phycocyanin

The arrows represent the direction of the changes in absorption maxima and $E_{620} / E_{280}$ ratios. For example, in fraction 2 the $625 \mathrm{~m} \mu$ maxima appeared first and gradually shifted with increasing elution volume to $628 \mathrm{~m} \mu$ with a change in the $E_{620} / E_{280}$ ratio from $1 \cdot 2$ to $4 \cdot 6$. The species present were determined from analytical-ultracentrifuge sedimentation-velocity studies on each fraction, at a concentration of approx. $10 \mathrm{mg} . / \mathrm{ml}$.

\begin{tabular}{cccl} 
Fraction & $\begin{array}{c}\lambda_{\max } \text { of visible } \\
\text { peak }(\mathrm{m} \mu)\end{array}$ & $\begin{array}{c}E_{620} / E_{280} \\
\text { ratio }\end{array}$ & Species present \\
1 & Opalescent & approx. 1 & approx. 2s \\
2 & $625 \rightarrow 628$ & $1 \cdot 2 \rightarrow 4 \cdot 6$ & $17 \mathrm{~s}, 11 \mathrm{~s},{ }^{*} 6 \mathrm{~s}$ \\
3 & $625 \rightarrow 624$ & $4 \cdot 3 \rightarrow 4 \cdot 9$ & $17 \mathrm{~s}, * 11 \mathrm{~s}, * 6 \mathrm{~s}$ \\
4 & $625 \rightarrow 620$ & $3 \cdot 9 \rightarrow 3 \cdot 3$ & $17 \mathrm{~s}, 11 \mathrm{~s}, 6 \mathrm{~s}^{*}$ \\
5 & $617 \rightarrow 616$ & $3 \cdot 2 \rightarrow 1 \cdot 0$ & $6 \mathrm{~s}$ \\
& \multicolumn{3}{c}{$*$ Major constituent. }
\end{tabular}

Table 3. Effect of $\mathrm{pH}$ on sedimentation properties of phycocyanin

The protein concentration was approx. $15 \mathrm{mg} . / \mathrm{ml}$. in sodium phosphate buffer, $I 0 \cdot 1$.

\begin{tabular}{|c|c|c|}
\hline $\mathrm{pH}$ & $S_{20, \mathrm{w}}(\mathrm{s})$ & $\begin{array}{l}\text { Relative \% of } \\
\text { total area }\end{array}$ \\
\hline $5 \cdot 5$ & $\begin{array}{c}5 \cdot 59 \\
10 \cdot 4 \\
16 \cdot 0 \\
19 \cdot 5 \\
23 \cdot 8\end{array}$ & $\begin{array}{l}16 \\
12 \\
14 \\
39 \\
19\end{array}$ \\
\hline $6 \cdot 0$ & $\begin{array}{c}6 \cdot 20^{*} \\
11 \cdot 9^{*} \\
17 \cdot 8^{*} \\
22 \cdot 8^{*} \\
27 \cdot 1^{*}\end{array}$ & $\begin{array}{l}27, \dagger 15 \ddagger \\
12, \dagger 4 \ddagger \\
13, \dagger 9 \ddagger \\
24, \dagger 34 \ddagger \\
24,+37 \ddagger\end{array}$ \\
\hline $6 \cdot 5$ & $\begin{array}{c}5 \cdot 35 \\
10 \cdot 1 \\
15 \cdot 2 \\
18 \cdot 4 \\
23 \cdot 4\end{array}$ & $\begin{array}{r}19 \\
7 \\
8 \\
58 \\
8\end{array}$ \\
\hline $6 \cdot 5 \S$ & $\begin{array}{c}5 \cdot 21 \\
10 \cdot 5 \\
16 \cdot 8 \\
18 \cdot 6\end{array}$ & $\begin{array}{r}20 \\
7 \\
3 \\
70\end{array}$ \\
\hline $7 \cdot 0$ & $\begin{array}{c}5 \cdot 51 \\
10 \cdot 4 \\
17 \cdot 0\end{array}$ & $\begin{array}{r}20 \\
9 \\
72\end{array}$ \\
\hline $8 \cdot 0$ & $\begin{array}{c}5 \cdot 15 \\
9 \cdot 88 \\
14 \cdot 5\end{array}$ & $\begin{array}{l}60 \\
20 \\
20\end{array}$ \\
\hline
\end{tabular}

* These are $S_{20, \text { w }}^{0}$ values.

$\dagger$ These areas were observed with a total protein concentration of approx. $15 \mathrm{mg} . / \mathrm{ml}$.

† These areas were observed with a total protein concentration of approx. $26 \mathrm{mg} . / \mathrm{ml}$.

$\S$ This sample was freeze-dried and reconstituted three times. areas under the schlieren peaks were somewhat sensitive to total protein concentration. Typical results for two different concentrations at $\mathrm{pH} \mathrm{6 \cdot 0}$ are given in Table 3. As the total protein concentration decreased, the relative amount of lower aggregates increased. The effect of pressure on the relative area under these peaks was investigated at pH 6.0. Various amounts of mineral oil were layered over the top of the protein sample as described by Josephs \& Harrington (1966), and the sedimentation was observed. Under these conditions no differences in relative areas under the peaks were evident.

Plots of the sedimentation coefficient versus concentration for all five species present at $\mathrm{pH} 6 \cdot 0$ are given in Fig. 2. The coefficients at individual concentrations of Phormidium luridum phycocyanin at $\mathrm{pH} 6 \cdot 0,7 \cdot 0$ and $8 \cdot 0$ agreed well with those determined for phycocyanin from Plectonema calothricoides (Scott \& Berns, 1965). This agreement is to be expected from the almost identical behaviour of the proteins from these two sources (Berns, 1967). It was found, also, that the $\mathrm{d} S / \mathrm{d} c$ values for the $7 \mathrm{~s}$ and $11 \mathrm{~s}$ species of phycocyanin from Phormidium luridum (Fig. 2) were similar to those for phycocyanin from Plectonema calothricoides.

The effect of repeated freeze-drying on the amount of the several aggregates was investigated and it was found that the chief effect was the disappearance of the $27 \mathrm{~s}$ species (Table 3 ).

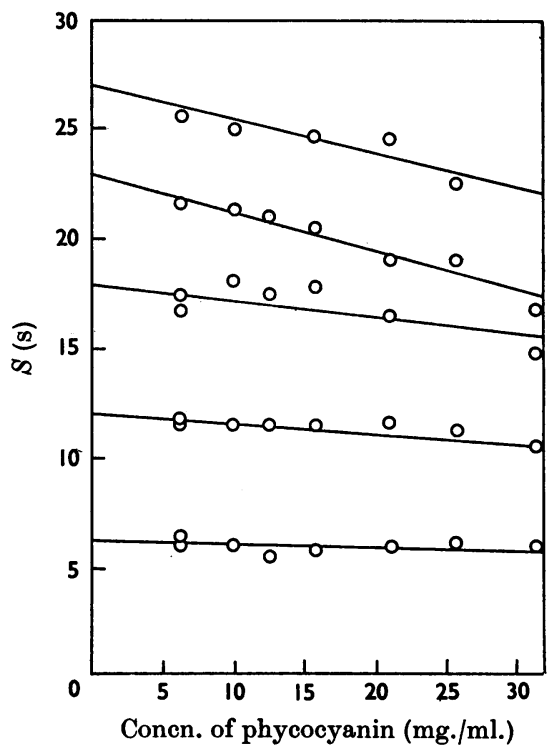

Fig. 2. Plot of sedimentation coefficient as a function of concentration for the observed species in phycocyanin from Phormidium luridum at $\mathrm{pH} 6 \cdot 0$ and $I 0 \cdot 1$ at $20^{\circ}$. 
Sucrose-density - gradient sedimentation. The species found on sucrose-density-gradient sedimentation were essentially those detected by the conventional analytical sedimentation-velocity method, except that larger aggregates were present in smaller amounts in the sucrose-density-gradient experiments. Increasing the sedimentation time resulted in the eventual disappearance of the species sedimenting faster than $11 \mathrm{~s}$ and the $11 \mathrm{~s}$ species becoming the major component (Table 4). The fraction that sedimented most slowly, approx. $6 \mathrm{~s}$, always contained the distinct allophycocyanin $654 \mathrm{~m} \mu$ absorption maximum. The greatest amount of material with an $E_{620} / E_{280}$ ratio 4.0 or greater was found in experiments with the largest amount of rapidly sedimenting species. The resolution of allophycocyanin from the higher aggregates resulted in low $\boldsymbol{E}_{620} / \boldsymbol{E}_{280}$ ratios and the dissipation of higher aggregates. An experiment was performed in which the entire sucrose density gradient contained phycocyanin at about $1 \mathrm{mg} . / \mathrm{ml}$. The sample layered on this gradient produced a greater resolution of peaks and a substantially larger amount of higher aggregates or species moving with the advancing front. Much larger $E_{620} / E_{280}$ ratios were also present throughout the gradient. The observation, in sucrose-density-gradient studies, of longerwavelength absorption maxima in the $620 \mathrm{~m} \mu$ region and greater $E_{620} / E_{280}$ ratios associated with higher aggregates confirmed conventional analytical sedimentation-velocity studies. In those studies once the higher aggregates were sedimented to the bottom of the centrifuge cell the sedimentation was stopped and the top and the bottom of the cell were examined in a spectrophotometer. The bottom of the cell contained material with a higher $E_{620} / E_{280}$ ratio, often as high as $5 \cdot 0$, and the absorption maximum in the visible region was at a wavelength longer than $625 \mathrm{~m} \mu$.

Fluorescence. The fluorescence properties of fractions from the sucrose-density-gradient centrifugation experiments (Fig. 3) were examined. The results of typical excitation-spectra studies are shown in Fig. 4. At $600 \mathrm{~m} \mu$ and longer wavelengths there were at least three fluorescence-excitation maxima for fluorescence emission monitored at

Table 4. Sucrose-density-gradient sedimentation experiments with phycocyanin

The relative amount is determined from comparisons of the areas under the graphs of plots of extinction versus tube fraction. Since these amounts are only estimates, as the species are not completely resolved (Fig. 2), the following designations are used: trace for approx. $5 \%$ or less; minor for less than approx. $20 \%$; major for greater than $20 \%$. These designations are arbitrary, except in one experiment $(6.5 \mathrm{hr}$.) where the exact percentages determined by the procedure are tabulated. The arrows represent the direction of the changes in absorption maxima and $E_{620} / E_{280}$ ratios. For example, in the $21 \mathrm{~s}$ fraction, after $4 \mathrm{hr}$. of sedimentation, the leading edge had an $E_{620} / E_{280}$ ratio 0.5 , which increased to 4.4 in later parts of the same peak with shifts of the absorption maximum from 633 to $625 \mathrm{~m} \mu$. Protein samples layered on the gradient were approx. $15 \mathrm{mg} . / \mathrm{ml}$. in $0 \cdot 2 \mathrm{ml}$.

\begin{tabular}{|c|c|c|c|c|}
\hline Time (hr.) & $S_{20, \mathrm{w}}(\mathrm{s})$ & Relative amount & $E_{620} / E_{280}$ ratio & $\lambda_{\max }(\mathrm{m} \mu)$ \\
\hline 4 & $\begin{array}{r}21 \\
15 \\
12 \\
6\end{array}$ & $\begin{array}{l}\text { Minor } \\
\text { Major } \\
\text { Major } \\
\text { Minor }\end{array}$ & $\begin{array}{l}0.5 \rightarrow 4.4 \\
4.1 \rightarrow 5.2 \\
4.2 \rightarrow 3.0 \\
3.0 \rightarrow 1.5\end{array}$ & $\begin{aligned} 633 & \rightarrow 625 \\
& 624 \\
& 624 \\
621 & \rightarrow 618^{*}\end{aligned}$ \\
\hline 6.5 & $\begin{array}{r}20 \\
17 \\
15 \\
9 \\
7\end{array}$ & $\begin{array}{r}5 \\
29 \\
38 \\
12 \\
16\end{array}$ & $\begin{array}{l}0.67 \rightarrow 4.8 \\
4.9 \rightarrow 5.5 \\
5.4 \rightarrow 4.1 \\
3.7 \rightarrow 3.2 \\
3.2 \rightarrow 1.0\end{array}$ & $\begin{array}{c}632 \rightarrow 626 \\
623 \\
622 \\
619 \\
618^{*}\end{array}$ \\
\hline $\begin{array}{l}\text { 6.5 } \\
\text { (plus } 1 \mathrm{mg} . \text { of } \\
\text { phycocyanin } / \mathrm{ml} \text {. } \\
\text { in gradient) }\end{array}$ & $\begin{array}{r}20 \\
18 \\
16 \\
13 \\
11 \\
6\end{array}$ & $\begin{array}{l}\text { Trace } \\
\text { Minor } \\
\text { Major } \\
\text { Major } \\
\text { Minor } \\
\text { Major }\end{array}$ & $\begin{array}{ll} & 4 \cdot 1 \\
4 \cdot 1 & \rightarrow 4 \cdot 2 \\
4 \cdot 5 & \rightarrow 4 \cdot 1 \\
4 \cdot 2 & \rightarrow 4 \cdot 0 \\
3 \cdot 5 & \rightarrow 3 \cdot 0 \\
2 \cdot 8 & \rightarrow 2 \cdot 5\end{array}$ & $\begin{array}{c}623 \\
623 \\
623 \\
624 \rightarrow 623 \\
623 \rightarrow 622 \\
621 \rightarrow 619^{*}\end{array}$ \\
\hline 10 & $\begin{array}{r}16 \\
14 \\
11 \\
7\end{array}$ & $\begin{array}{l}\text { Trace } \\
\text { Major } \\
\text { Minor } \\
\text { Major }\end{array}$ & $\begin{array}{l}1.0 \rightarrow 1.4 \\
2.5 \rightarrow 4.1 \\
3.5 \rightarrow 2.3 \\
2.4 \rightarrow 0.4\end{array}$ & $\begin{array}{c}630 \rightarrow 622 \\
622 \\
621 \\
620 \rightarrow 618^{*}\end{array}$ \\
\hline 18 & $\begin{array}{r}11 \\
7\end{array}$ & $\begin{array}{l}\text { Major } \\
\text { Major }\end{array}$ & $\begin{array}{l}5.2 \rightarrow 4.5 \\
3.7 \rightarrow 0.4\end{array}$ & $\begin{array}{l}633 \rightarrow 624 \\
619 \rightarrow 615^{*}\end{array}$ \\
\hline
\end{tabular}

* Allophycocyanin shoulder appeared in these fractions. 


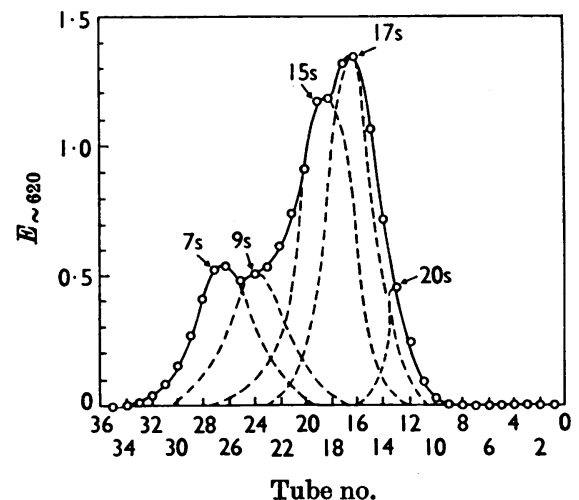

Fig. 3. Typical sucrose-density-gradient sedimentation experiment with phycocyanin. Extinction of fractions at the visible-absorption maximum (approx. $620 \mathrm{~m} \mu$ ) is plotted as a function of tube number. The experiment shown was with a sample, $\mathrm{pH} 6.0$ and $I 0 \cdot 1$, centrifuged at $39000 \mathrm{rev} . / \mathrm{min}$. in the $\mathrm{SW} 39$ rotor for $6.5 \mathrm{hr}$., the same as in Table 4.

$650 \mathrm{~m} \mu$. These excitation maxima were at approx. $590-600 \mathrm{~m} \mu$ and $620-630 \mathrm{~m} \mu$, with a shoulder at above $640 \mathrm{~m} \mu$. The $620-630 \mathrm{~m} \mu$ excitation is predominant with the fractions containing the highest aggregates and there is some indication of $600 \mathrm{~m} \mu$ excitation (Fig. 4a). Samples containing more lower aggregates exhibit a greater contribution of the $600 \mathrm{~m} \mu$ excitation (Figs. $4 c, 4 d$ and $4 e$ ). Fractions that contain the allophycocyanin shoulder exhibit the excitation shoulder near $640 \mathrm{~m} \mu$ (Fig. $4 d$ ). Experiments with samples possessing a predominant allophycocyanin spectrum demonstrated that the fluorescence excitation at wavelengths longer than $640 \mathrm{~m} \mu$ is probably associated with the allophycocyanin-type absorption. In addition, the emission maximum shifted to wavelengths as long as $680 \mathrm{~m} \mu$ in samples principally of the allophycocyanin type. Apparently the fluorescence emission is always a single symmetric band (Fig. 5). Table 5 shows that the position of the emission maximum shifted slightly towards shorter wavelengths with decreasing sedimentation coefficient of the fraction examined. The fraction containing the allophycocyanin had a shift of fluorescence emission to slightly longer wavelengths.

\section{DISCUSSION}

The sedimentation-velocity data indicate that very large phycocyanin aggregates are present in crude algal extracts and that careful purification will produce samples containing all the higher

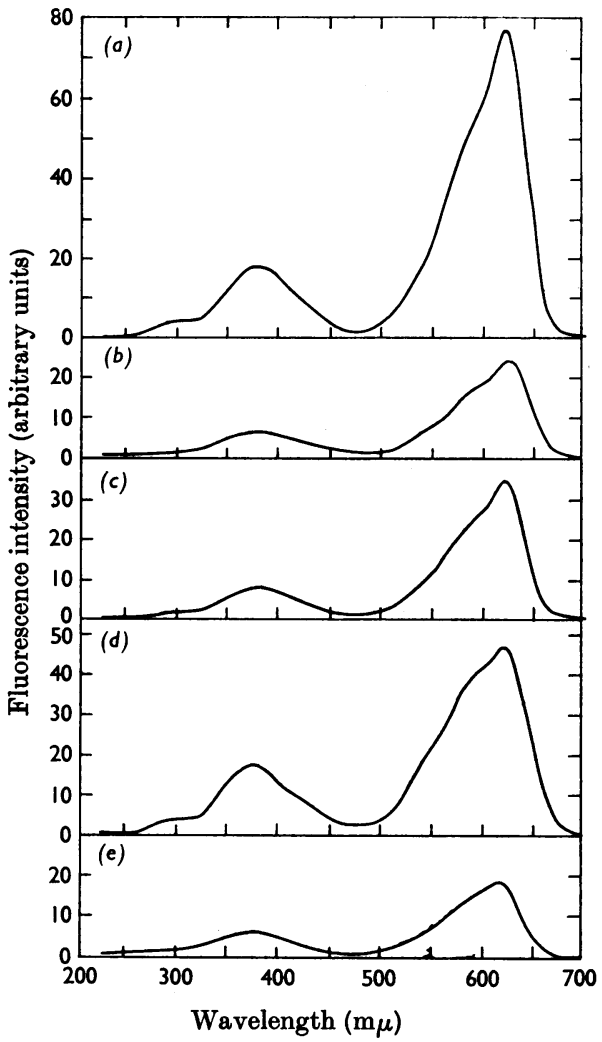

Fig. 4. Typical fluorescence-excitation spectra of phycocyanin fractions from a sucrose-density-gradient experiment (pH6.0 and $I 0.1$; sedimentation at $39000 \mathrm{rev} . / \mathrm{min}$. in the SW 39 rotor for $6.5 \mathrm{hr}$.). The fluorescence at $650 \mathrm{~m} \mu$ is measured in arbitrary units as a function of exciting wavelength. The concentrations in $(a),(b),(c),(d)$ and $(e)$ are not equal and are those of the undiluted sucrose-densitygradient fractions. The fractions that correspond to those in Fig. 3 and Table 5 are: $(a)$ approx. $17 \mathrm{~s}$, tube no. 16; (b) approx. $22 \mathrm{~s}$, tube no. 12; (c) approx. $16 \mathrm{~s}$, tube no. 18; (d) $8 \mathrm{~s}$, tube no. 26 ; (e) $<6 \mathrm{~s}$, tube no. 30 .

aggregates in greater concentrations. The elimination of species that sedimented most slowly and enhancement of higher aggregates result in spectral properties usually associated with very pure phycocyanin preparations, namely a high $\boldsymbol{E}_{620} / \boldsymbol{E}_{\mathbf{2 8 0}}$ ratio, a narrower visible-absorption band width and a high relative fluorescence efficiency. The presence of several aggregates sedimenting faster than $11 \mathrm{~s}$ and their interaction may be explained by the following equilibria, where $M$ represents the monomer sub-unit of 30000 (the extrapolated value for the $M_{18}$ species is $27 \mathrm{~s}$, but at finite protein concentrations this species may sediment as slowly as $22 \mathrm{~s}$. In a similar fashion the extrapolated value 
for the $M_{12}$ species is $22 \cdot 8 \mathrm{~s}$, but the value may be as low as $18.9 \mathrm{~s}$ at finite concentrations):

$$
\begin{aligned}
& M_{18}(27 s) \rightleftharpoons M_{12}(22 s)+M_{6}(11 s) \\
& M_{18}(27 s) \rightleftharpoons 2 M_{9}(16 s) \\
& M_{12}(22 s) \rightleftharpoons 2 M_{6}(11 s) \\
& M_{9}(16 s) \rightleftharpoons M_{6}(11 s)+M_{3}(6 s) \\
& M_{6}(11 s) \rightleftharpoons 2 M_{3}(6 s) \\
& M_{6}(11 s) \rightleftharpoons 6 M(3 s) \\
& M_{3}(6 s) \rightleftharpoons 3 M(3 s)
\end{aligned}
$$

These equilibria represent an attempt to clarify the relationship between the various components resolved in the ultracentrifuge. They take into account data on phycocyanin aggregation (Scott \& Berns, 1965; Berns \& Scott, 1966; Berns \& Morgenstern, 1966) and the changes in the relative amount of aggregates observed as a function of $\mathrm{pH}$, e.g. as the amount of $27 \mathrm{~s}$ component decreases there is an enhancement of $22 \mathrm{~s}$ species. The largest phycocyanin aggregates begin to approximate the size of the biliprotein particles found by Gantt \& Conti (1967) in Porphyridium cruentum and the hexameric array reported by Luftig \& Haselkorn (1967) in phage-lysed blue-green algae.

In sucrose-density - gradient sedimentation experiments, although some very high aggregates were shown to be present in samples sedimented for

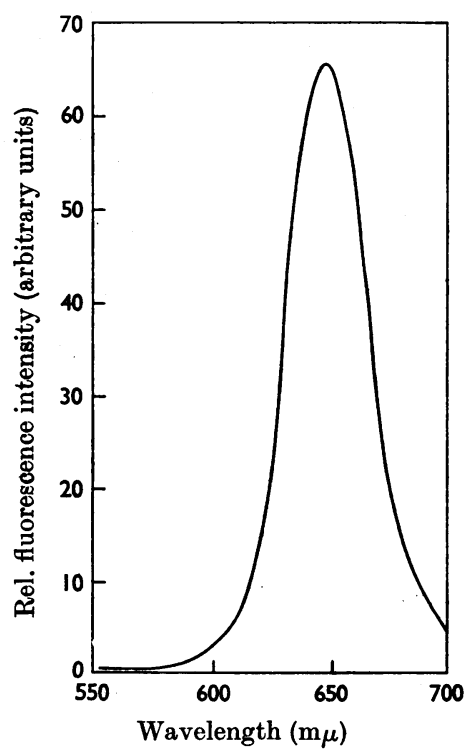

Fig. 5. Typical fluorescence-emission spectrum of a fraction from a sucrose density gradient, approx. $16 \mathrm{~s}$, tube no. 18 , from Figs. 3 and 4. Excitation is at the visible-absorption maximum, in this case $622 \mathrm{~m} \mu$; the emission maximum is $646 \mathrm{~m} \mu$.
$4 \cdot 5-6 \cdot 5 \mathrm{hr}$., the amount was smaller than indicated by analytical sedimentation velocity. After $18 \mathrm{hr}$. the $17 \mathrm{~s}$ species was not detected. Sephadex-gelfiltration treatment resulted in disaggregation of the highest aggregates. In each case when a method that is potentially band-separating was employed, the highest aggregates present in the advancing front were dissipated. This type of behaviour resembles the reaction that might be expected of a micelle exposed to a band-separation method. At the advancing front, the micelle would be dissipated as it progressed down the column. Since hydrophobic forces have been implicated as important in at least some of the aggregates in the phycocyanin system, in an analogy with micelle behaviour, the dissipation of higher aggregates on band separation might be expected. In a sucrose-density-gradient experiment it was demonstrated that, when a sample was layered on a gradient containing phycocyanin at a concentration of approx. $1 \mathrm{mg} . / \mathrm{ml}$. throughout, the sedimentation resulted in enhancement of higher aggregates and also better resolution of peaks (Table 4).

It is possible from current evidence to demonstrate that the presence of the very large phycocyanin aggregates is not simply a concentration-dependent phenomenon. Gel-filtration experiments with samples with large amounts of $24 \mathrm{~s}$ material result in resolution of the sample into fractions successively predominant in $11 \mathrm{~s}, 17 \mathrm{~s}$ and $6 \mathrm{~s}$ species (Table 2 ). Recombination and concentration of the entire sample did not result in the reappearance of $24 \mathrm{~s}$

\section{Table 5. Typical fuorescence study of phycocyanin}

The fractions correspond to tube numbers from the phycocyanin sucrose-density-gradient sample, pH6.0, sedimented for $6.5 \mathrm{hr}$. at $39000 \mathrm{rev} . / \mathrm{min}$. in the $S W 39$ rotor. The arbitrary relative fluorescence efficiency is calculated

\begin{tabular}{|c|c|c|c|c|}
\hline $\begin{array}{c}\text { Fraction } \\
\text { no. }\end{array}$ & $\begin{array}{l}\text { Approx. } \\
S_{20, \mathrm{w}}(\mathrm{s})\end{array}$ & $\begin{array}{c}\lambda_{\max } \text { of } \\
\text { visible } \\
\text { peak }(\mathrm{m} \mu)\end{array}$ & $\begin{array}{c}\lambda_{\max } \text { of } \\
\text { fluorescence } \\
\text { emission } \\
(\mathrm{m} \mu)\end{array}$ & $\begin{array}{c}\text { Relative } \\
\text { fluorescence } \\
\text { efficiency }\end{array}$ \\
\hline 12 & $>22$ & 629 & 650 & $29 \cdot 0$ \\
\hline 16 & 19 & 623 & 648 & $44 \cdot 6$ \\
\hline 18 & 16 & 622 & 646 & $49 \cdot 2$ \\
\hline 24 & 10 & 619 & 650 & $19 \cdot 7$ \\
\hline 26 & 8 & $619^{*}$ & 652 & $18 \cdot 4$ \\
\hline 30 & $<6$ & 617 & 646 & 13.9 \\
\hline
\end{tabular}
as being the ratio of the fluorescence-detector reading (in $\mu \mathrm{A}$ ) at the wavelength of the fluorescence maximum to the extinction at the visible-absorption maximum in a $1 \mathrm{~cm}$. cell. All spectrofluorimeter sensitivity settings were kept constant and the excitation wavelength was always that of the absorption maximum.

* This fraction has the most pronounced shoulder because of the presence of allophycocyanin. There may also be a small amount in fraction 24. 
material. In purification experiments when an almost completely purified sample is exposed to $20 \%$-saturated ammonium sulphate the supernatant is richer in $24 \mathrm{~s}$ aggregate than is the precipitate. Apparently to some extent the presence of lower-molecular-weight species is necessary for enhancement of the highest aggregates.

Boundary-separation experiments that result in the dissipation of the $27 \mathrm{~s}$ material, and eventually the $22 \mathrm{~s}$ material, also uncover an allophycocyanin fraction. Conditions that favour disaggregation of higher aggregates, such as repeated application of the same phycocyanin sample to a Sephadex G-200 column or longer times of sedimentation on sucrose density gradients, increase the amount of allophycocyanin present. Possibly the disaggregation of the highest aggregates under the conditions investigated causes an irreversible conformational change indicated by the presence of this allophycocyanin fraction, explaining why reconstitution does not result in reaggregation.

In fluorescence studies higher aggregates always resulted in an excitation peak with a maximum near $630 \mathrm{~m} \mu$ with no indication of a shoulder on the long-wavelength side (Fig. $4 a$ ), but with a definite shoulder on the short-wavelength side near $600 \mathrm{~m} \mu$. The $600 \mathrm{~m} \mu$ excitation became more pronounced as the degree of aggregation decreased. Only when the allophycocyanin absorption was detectable did the shoulder above $640 \mathrm{~m} \mu$ become discernible. Fluorescence experiments with native phycocyanin, disaggregated phycocyanin and allophycocyanin substantiated the correlation of the short-wavelength excitation with the disaggregated protein, the longwavelength excitation with the allophycocyanin fraction and the $630 \mathrm{~m} \mu$ excitation with higher aggregates. In all experiments, no matter how complex the excitation spectrum, there was always only one apparently symmetrical fluorescenceemission band. The position of the emission maximum shifted to slightly longer wavelengths with increasing aggregation. In samples with predominant allophycocyanin spectra, excitation at 620 or $650 \mathrm{~m} \mu$ resulted in a single fluorescence peak with a maximum near $680 \mathrm{~m} \mu$. Internal energy transfer occurs sufficiently fast in this system so that only one oscillator or predominantly one kind of oscillator emits, even though more than one kind may absorb. Consequently, if in allophycocyanin one chromophore has been twisted from its native conformation and we assume that at least two chromophores exist per minimal sub-unit, we would predict a relatively lower fluorescence efficiency for allophycocyanin-containing fractions. This is indeed the observed behaviour (Table 5). The existence of only a single fluorescence-emission band under conditions where several distinct excitation peaks are found argues strongly for considering the C-phycocyanin-allophycocyanin system as a single protein system.

In algal extracts in which significantly larger amounts of allophycocyanin are found, e.g. Synechoccocus lividus, the phycocyanin was much more disaggregated under normal purification conditions. Anacystis nidulans has been reported by Neufeld (1966) not to contain allophycocyanin. Preliminary studies in our Laboratory indicate that partially purified phycocyanin from this organism has about $80 \%$ of the sample present as $35 \mathrm{~s}$ material. This indeed is consistent with the suggestion that stabilization of very high aggregates is responsible for the absence of allophycocyanin.

This work was supported in part by a grant from the National Science Foundation (GB-7591). The authors thank Dr Oranda Kao for supplying pertinent fluorescence data before their publication, Dr B. Pogell for the use of his Spinco model L-2 ultracentrifuge and Dr S. H. G. Allen for the use of his spectrofluorimeter. J.J.L. is a postdoctoral fellow under a grant from the U.S. Public Health Service, National Institutes of Health (1SO1 FR-0549-01).

\section{REFERENCES}

Andrews, P. (1964). Biochem. J. 91, 222.

Berns, D. S. (1967). Plant Physiol. 42, 1569.

Berns, D. S. \& Morgenstern, A. (1966). Biochemistry, 5, 2985.

Berns, D. S. \& Scott, E. (1966). Biochemistry, 5, 1528.

Eriksson-Quensel, I.-B. (1938). Biochem. J. 82, 585.

Gantt, E. \& Conti, S. F. (1967). Brookhaven Symp. Biol. $19,393$.

Hattori, A. \& Fujita, Y. (1959). J. Biochem., Tokyo, 46, 633.

Josephs, R. \& Harrington, W. F. (1966). Biochemistry, 5, 3474.

Luftig, R. \& Haselkorn, R. (1967). J. Virol. 1, 344.

Martin, R. G. \& Ames, B. N. (1961). J. biol. Chem. 236, 1372.

Neufeld, G. (1966). Ph.D. Thesis: University of Texas.

6 hEocha, C. (1962). In Physiology and Biochemistry of Algae, p. 421. Ed. by Lewin, R. A. New York: Academic Press Inc.

6 hEocha, C. (1965). In Chemistry and Biochemistry of Plant Pigments, p. 175. Ed. by Goodwin, T. W. New York: Academic Press Inc.

Scott, E. \& Berns, D. S. (1965). Biochemistry, 4, 2597. Scott, E. \& Berns, D. S. (1967). Biochemistry, 6, 1327. 